\title{
Oral Cancer Awareness among Medical \& Dental Students of Bahria University Medical and Dental College
}

\author{
Beenish Fatima Alam ${ }^{1}$ \\ Madiha Anwar ${ }^{2}$ \\ Talha Nayab ${ }^{3}$ \\ Marium Azfar ${ }^{4}$ \\ Peraha Shaikh ${ }^{5}$ \\ Ahmer Shakeel $^{6}$ \\ BDS, MSc, MFDS RCSEd \\ BDS, MDS \\ BDS, MSc \\ BDS, MPH \\ Final Year Student \\ Final Year Student
}

OBJECTIVE: Pakistan has a high rate of incidence of oral cancer. In Pakistan, betel nut, betel quid and tobacco are found to be the most important causative agents of oral cancer. Timely detection and diagnosis of oral cancers can improve their responsive to treatments, consequently decreasing mortality rate and increasing the prognosis rate. The objective of this study was to report the knowledge and information about the different causes, risk factors and clinical appearance of oral cancer among undergraduate dental and medical students and to further identify the changes and improvements required in the teaching strategies.

METHODOLOGY: A cross-sectional survey was done among 400 medical and dental undergraduate students of Bahria Medical and Dental University Karachi. The tool used to evaluate awareness of oral cancer was a self-administered questionnaire taken from Carter to Odgen. The collected data was analyzed by SPSS software (v-16) to calculate mean descriptive and percentages of the awareness about causes and early signs of oral cancer among undergraduate students. RESULTS: Students of dentistry were found to have a habit of examining the oral mucosa as compared to the medical students. Betel nut chewing and tobacco were the commonly identified risk factors. Non-healing ulcer was recognized as the common clinical change pertaining to oral cancer. Out of all students, only $6 \%$ were found to be very well informed. CONCLUSION: This study suggests that curriculum of medical and dental students should be improved by incorporating more interactive teaching sessions such as seminars, OPD training sessions and awareness programs for oral cancer. More emphasis should be given on oral examination by medical students during their clinical years to enhance their knowledge about oral cancer improving its prognosis.

KEYWORDS: Oral Cancer, Awareness, Risk Factors, Undergraduate Students, Oral Mucosal Changes, Diagnosis, Medical, Dental

HOW TO CITE: Alam BF, Anwar M, Nayab T, Azfar M, Shaikh P, Shakeel A. Oral cancer awareness among Medical \& Dental Students of Bahria University Medical and Dental College. J Pak Dent Assoc 2018;27(4):172-80.

DOI: https://doi.org/10.25301/JPDA.274.172

Received: 11 June 2018, Accepted: 17 August 2018

\section{INTRODUCTION}

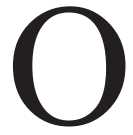
ral cancer ranks at eighth among all cancers ${ }^{1}$, with an increased incidence reported within the developing South Asian countries. ${ }^{2,3}$

1. Assistant Professor, Department of Oral Biology, Bahria University Medical and Dental College.

2. Lecturer, Department of Oral Biology, Bahria University Medical and Dental College.

3. Assistant Professor, Department of Oral Biology, Jinnah Sindh Medical University.

4. Associate Professor, Department of Community Dentistry, Jinnah Sindh Medical University.

5. Student, Bahria University Medical and Dental College.

6. Student, Bahria University Medical and Dental College.

Corresponding author: "Dr. Madiha Anwar" < madeeha.anwar@gmail.com >
Oral cancer, with its highly unpredictable level of incidence at present is one of the commonest cancerous conditions effecting the general population of Pakistan. Cancer of oral cavity and lip is responsible for $8.6 \%$ of all new cancer cases in Pakistan and is the cause $7.2 \%$ of all cancer deaths in Pakistan. ${ }^{3}$ In the south Asian countries such as Pakistan and India nearly $66.4 \%$ of all cancers are located within the oral cavity and lip and the cancers of oral cavity are responsible for causing deaths in $77.2 \%$ of the individuals. ${ }^{4}$ The findings published by Shaukat Khanum Cancer Hospital, Lahore identified that the malignant neoplasms of oral cavity are the third commonly occurring 
cancer followed by breast and ovarian cancer within Pakistani females. Furthermore, oral cancer was found to be second most common cancer in males after prostate cancer. ${ }^{5}$

Oral cancer can have different presentations ranging from ulcerative growths to proliferative lesions or even a combination of both. There are many pre malignant oral conditions, like leukoplakia, erythroplakia and oral submucous fibrosis. ${ }^{6,7}$ The most commonly affected sites involving the mouth are the floor and the lateral border of the tongue. ${ }^{8}$

In American and European countries, drinking alcohol and smoking tobacco are documented as the causative agents for oral cancer ${ }^{9}$ but within developing Asian countries the main carcinogenic influence are betel nut, areca nut and other addictives. World Health Organization (WHO) also states that alcohol consumption, tobacco and other risk factors have $43 \%$ role in all cancer deaths. ${ }^{10}$ Socioeconomic status also plays and important role in the development of oral cancer. ${ }^{11}$ Other known etiological factors include Human Papilloma Virus infection ${ }^{6}$ and nutritional deficiency. ${ }^{12}$

Different studies conducted in Florida, India and Malaysia. ${ }^{13-15}$, regarding awareness of general population on oral cancer have revealed poor response about the signs and the risk factors of oral cancer and it is one of the main reasons of poor prognosis of this disease. ${ }^{16}$ Similarly insufficient information related to initial stages of cancer of oral cavity, its causes and preventive measures among the medical practitioners is another significant factor in delayed treatment and management of the disease.${ }^{17}$ Studies conducted in different countries have shown that dentists and dental students are more aware of premalignant conditions as well as etiological factors responsible for oral cancer as compared to medical students and practitioners. ${ }^{6,16,17}$ Pakistan has limited data regarding awareness of oral cancer in dental and medical students. A study conducted in Lahore focused only on awareness of dental students about the causes, risk factors and clinical presentation of oral cancer ${ }^{18}$ while no studies related to oral cancer awareness have been conducted among medical students of Pakistan.

Increased incidence of oral cancer within Pakistan requires awareness and teaching of the medical and dental students to not only decrease the mortality of oral cancer but also diagnose it at an early stage. Hence, this study aims to report awareness of undergraduate medical and dental students related to oral cancer, its etiology and preventive causes. This information may help in reconsidering different aspects of curriculum for medical and dental students.

\section{METHODOLOGY}

This cross-sectional study was conducted to understand the level of knowledge regarding oral cancer among under graduate medical and dental students. The study was conducted over a period of five months among 400 medical and dental undergraduate students of Bahria University Medical and Dental College. Student selection was based on the fact that, second year, third year and final year students of BDS and MBBS are expected to have sufficient knowledge regarding oral cancer as they are taught about the etiology and pathology of oral cancer in their curriculum. Students of 1st and 2nd year MBBS and 1st year BDS were excluded, as they would not have sufficient clinical exposure. A formal approval of study was taken from Ethical Review Committee of Bahria University Medical and Dental College (Reference no. ERC 07/2018) before conducting the study. The main aim of the study was explained to the students and verbal consent was taken from them before distributing the questionnaires. Participation of the students was voluntary. Approximately ten minutes were required for the completion of the questionnaire which has been taken from the study conducted by Carter and Ogden. ${ }^{15}$

The first part of questionnaire included the sociodemographic details of the participant such as age, gender, and year of study at medical or dental college.

The next part of questionnaire focused on twelve questions related to habitual oral mucosal examination, knowledge regarding the risk factors and clinical appearance of oral cancers and inspecting patients with oral lesions. The questionnaire further evaluated opinions on competency of early detection and prevention of cancer of oral cavity, need for additional education and information programs and the mode of information needed for more assistance.

\section{STATISTICAL ANALYSIS}

Sample size was calculated using OpenEpi ${ }^{\mathrm{TM}} 3$. All the responses were coded and statistical analysis was done by SPSS 17. Descriptive statistics were done for all variables and Chi-square test was applied to analyze the association between the responses of the medical students and the responses given by the dental students. The p-value less than 0.05 was taken as significant.

\section{RESULTS}

Questionnaires were distributed in a total of 400 students, out of which $22 \%(n=88)$ were males and $78 \%(n=312)$ were females. All questionnaires were returned and response rate was found to be $100 \%$ as students who participated were instructed to answer all the questions. The average age of students was around $21.6( \pm 2.5)$.

In response to the questions related to routine examination of oral mucosa significant difference was found between the 
students as more students of dentistry $(67.5 \%)$ than students of medicine $(3.5 \%)$ responded positively $(p-v a l u e=0.000)$. Fig 1(a\&b) shows the distribution of the dental and medical students who routinely examine dental mucosa. Out of the $56.75 \%$ students who regularly did not examine oral mucosa, $85.4 \%$ agreed to inspect the oral mucosa of high risk cancer patients.

Majority of the respondents identified smoking (26\%) and betel nut $(25.5 \%)$ as risk factors of oral cancer. Fig. 2 shows dissemination of other risk factors such as ghutka, nutritional deficiency, human papilloma virus, genetic predisposition that were identified by students while Fig. 3 and 4 shows identification of risk factors by medical and dental students studying in different years. More dental $(65 \%)$ as compared to medical students (33.5\%) informed having the chance to examine patients with oral lesions ( $p$-value $<0.05$ ). The question enquired about instructing the patients about the factors leading to oral cancer after completing their education, was responded positively by $96 \%$ dental and $92.5 \%$ medical students.

In response to the information related the clinical presentation of oral cancer, $51.0 \%$ of dental and $43.5 \%$ medical students felt that they had adequate information. Only $6 \%$ of the total students reported being very well informed. The commonly identified cancerous change in oral mucosa was non-healing ulcer followed by red and white lesions and oral submucous fibrosis. Other oral mucosal changes associated with oral cancer are shown in Fig. 5. Regarding referral of the patient with oral lesions, both dental (63.5\%) and medical (62\%) students agreed to refer

Fig 1a. SHOWS THE YEAR WISE DISTRIBUTION OF DENTAL STUDENTS WHO ROUTINELY EXAM INE ORAL MUCOSA

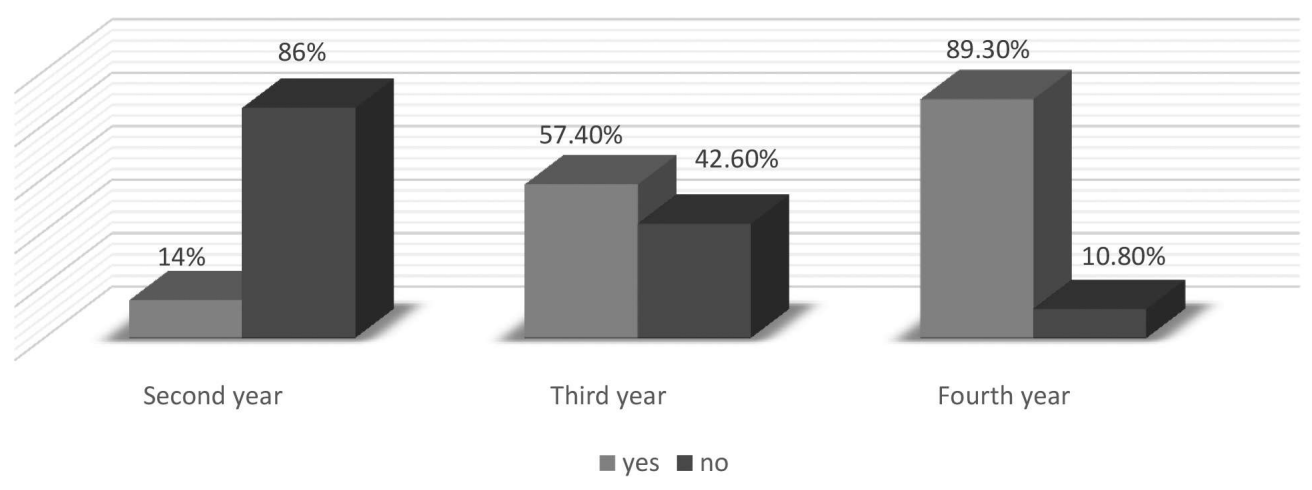

Fig 1b. SHOWS THE YEAR-WISE DISTRIBUTION OF MEDICAL STUDENTS WHO ROUTINELY EXAM INE ORAL MUCOSA

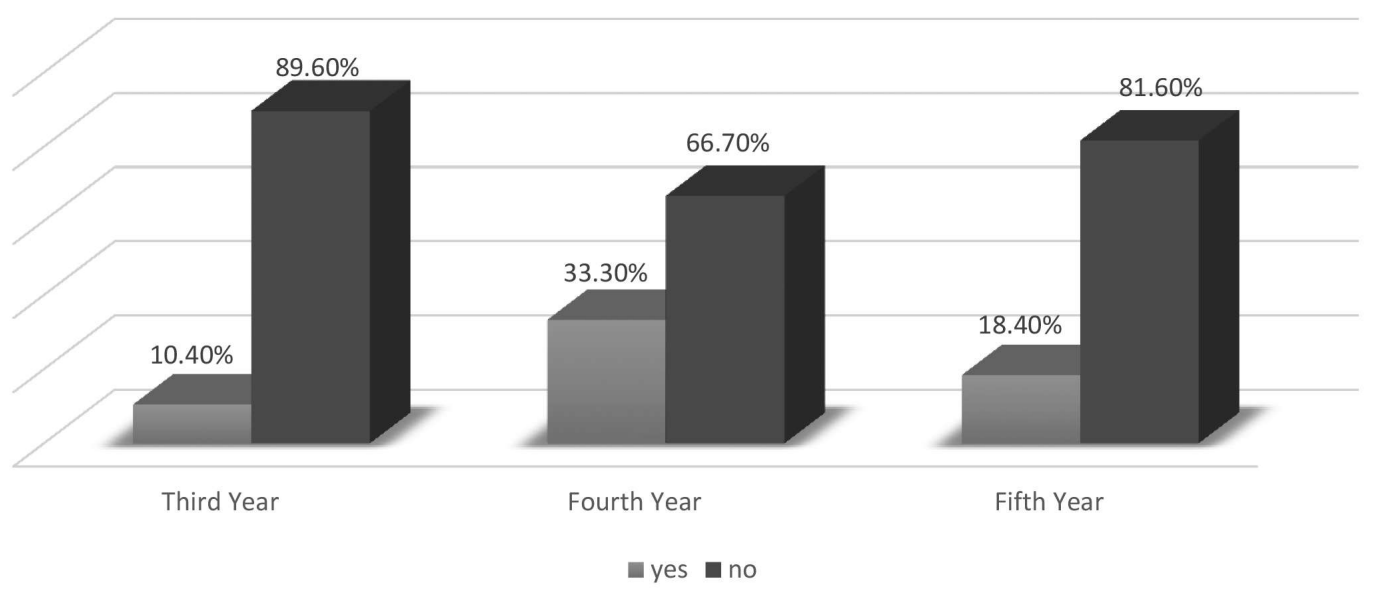


Fig 2. SHOWS THE PERCENTAGES OF DIFFERENT RISK FACTORS OF ORAL CANCER IDENTIFIED BY MEDICAL AND DENTAL STUDENTS

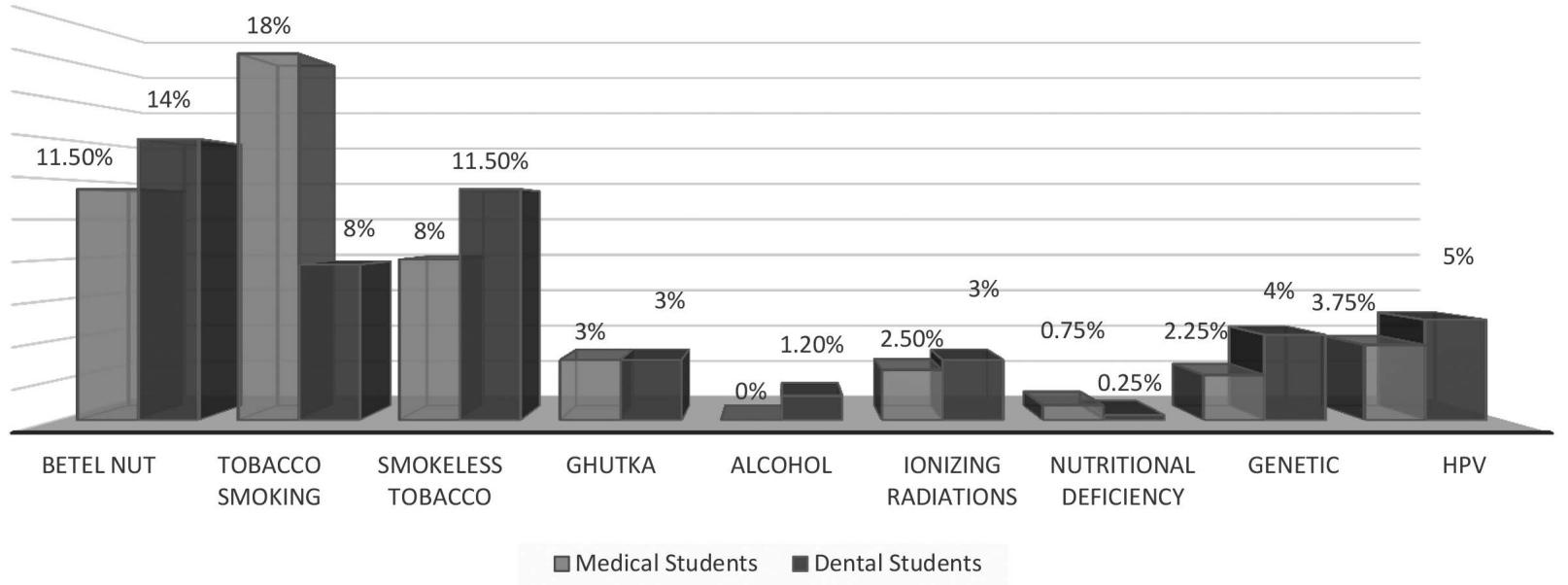

Fig 3. YEAR WISE DISTRIBUTION OF DENTAL STUDENTS IDENTIFYING DIFFERENT RISK FACTORS OF ORAL CANCER

$39.80 \%$

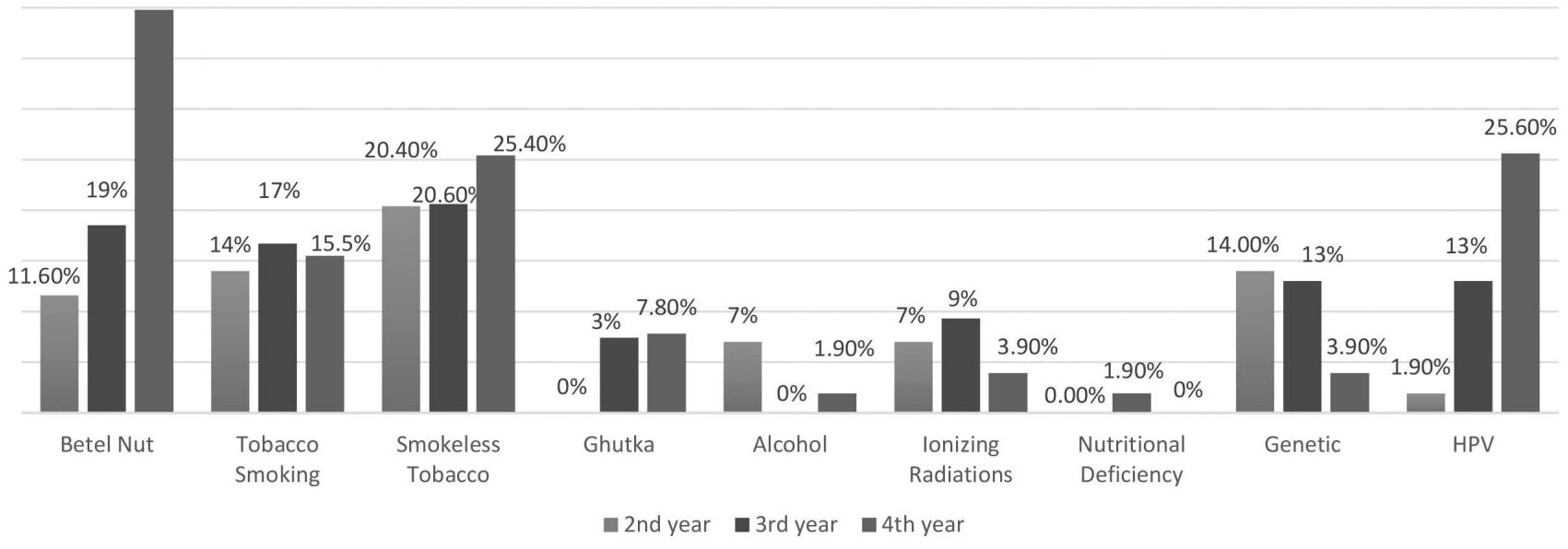

Fig 4. YEAR WISE DISTRIBUTION OF MEDICAL STUDENTS IDENTIFYING

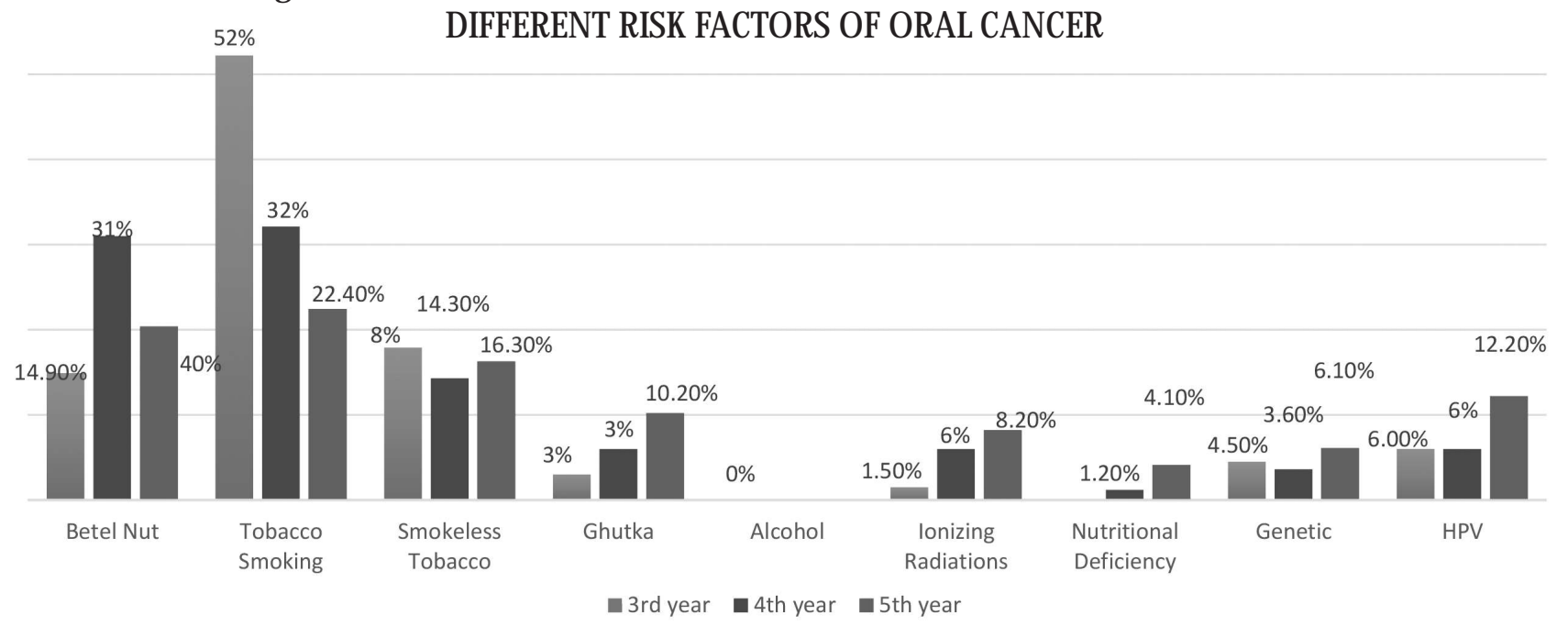


to a general dentist rather than a general physician. For referring patients suspected with oral malignant lesions, it was noted that oral maxillofacial surgery department $(57 \%)$ was the most preferred by both medical and dental students, followed by general dentist $(15.8 \%)$ and ear, nose and throat department (13.8\%).

Majority of the respondents $(92.5 \%)$ wanted to have additional knowledge and information on different aspects of oral cancer such as patient counselling, clinical presentation of oral cancer, its management and treatment. The preferred mode of getting information related to oral cancer was found to be seminars shown in Fig. 6.

\section{DISCUSSION}

Awareness of oral cancers is a very important topic yet it is often neglected by the general population, doctors and government alike. ${ }^{15,19,20}$ This study focused on knowing the differences in awareness and understanding among undergraduate students of medicine and dentistry, regarding the factors causing oral cancer, their clinical appearance and signs and symptoms that are present within the oral cavity. Dental students are exposed to oral lesions from second year onwards; hence, they have a better opportunity to timely diagnose the oral cancer along with its associated features

Fig 5. SHOWS DIFFERENT ORAL MUCOSAL CHANGES ASSOCIATED WITH ORAL CANCER IDENTIFIED BY MEDICAL AND DENTAL STUDENTS

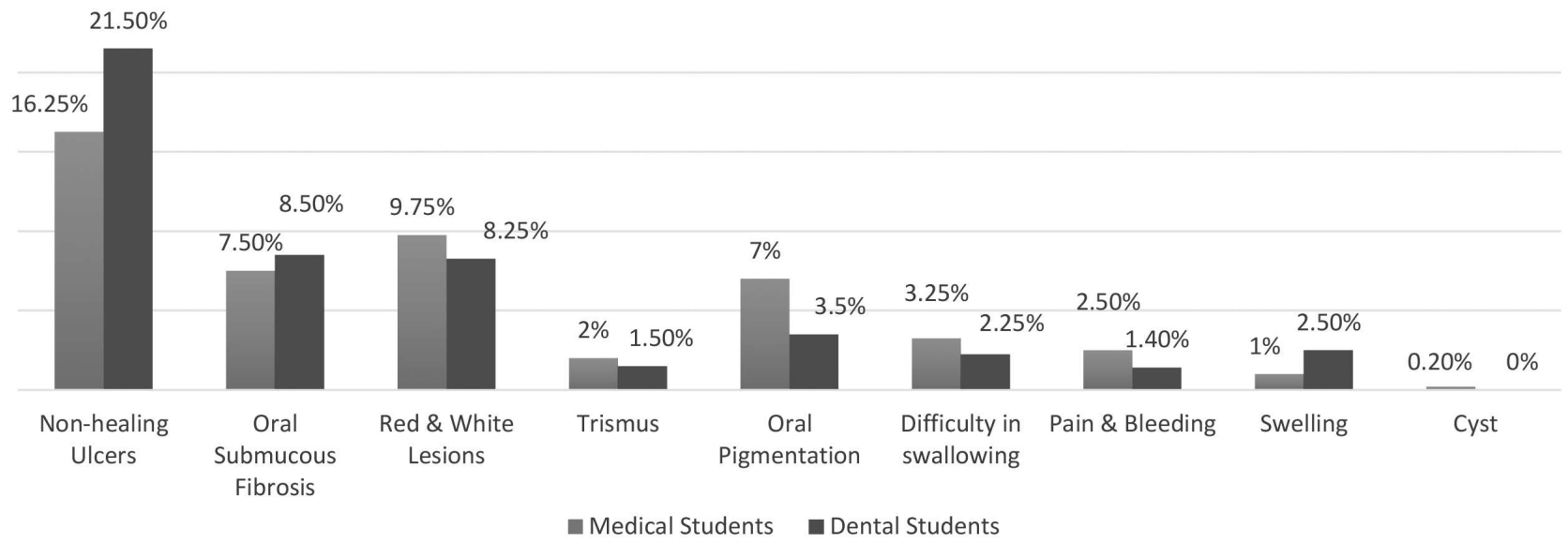

Fig 6. SHOWS THE PERCENTAGES OF DIFFERENT MODES OF GETTING FURTHER INFORM ATION ABOUT ORAL CANCER SELECTED BY MEDICAL AND DENTAL STUDENTS

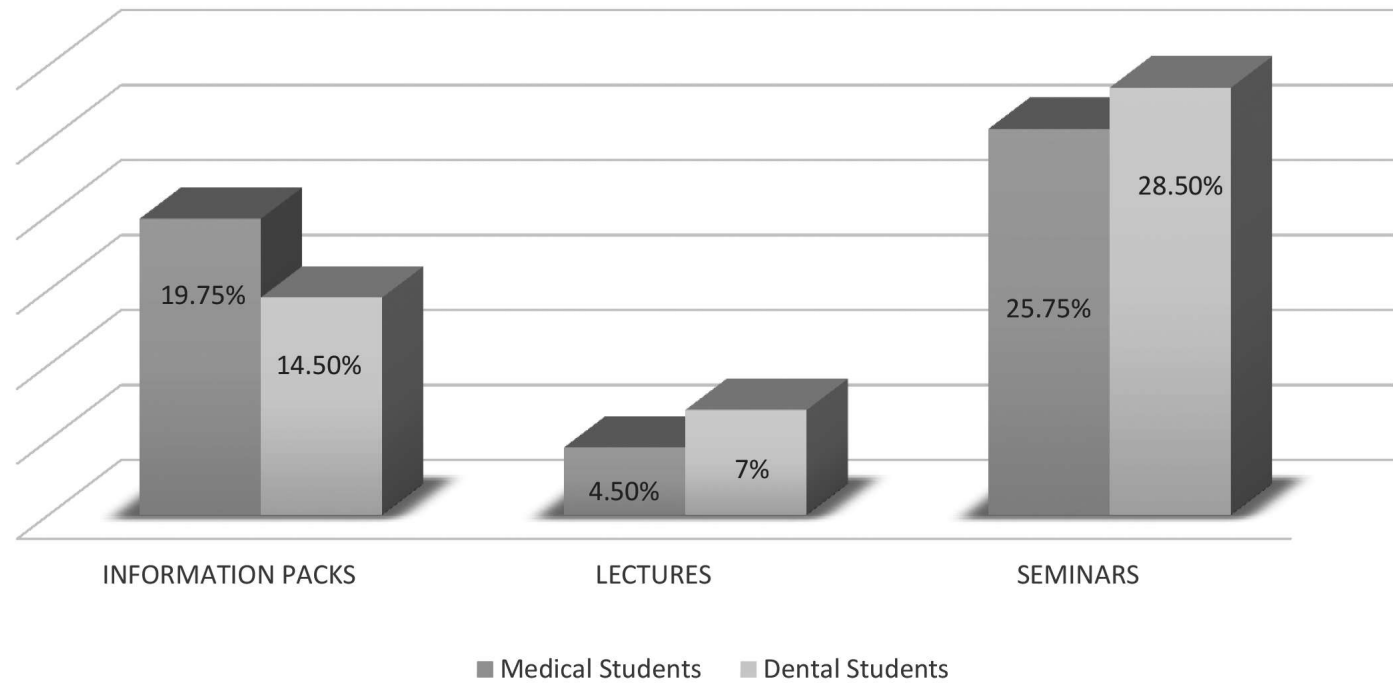


and different presenting complains. In this study it was found that considerably more dental students regularly inspect the oral mucosa when compared with the medical students. This could be due to the fact that dental students have to deal with lesions in oral cavity mainly while medical students and general medical practitioners mostly inspect the oral cavity of patients only when they are under consultation for oral problems. ${ }^{17}$ It was observed in our study that more final year dental students examined the patient's oral mucosa on regular basis as in this year the students have the most clinical exposure. On the other hand it was also observed that medical students tend to screen oral mucosa of patients who were at high risk of developing oral cancer. These findings were in correspondence to the study carried out by Yellowitz and Goodman $^{21,22}$, in which they concluded that medical students and practitioners normally examine the oral mucosa of the patients who are at high risk of oral cancer.

Several predisposing factors are involved in aetiology of oral cancer, predominantly it is related to frequent consumption of tobacco products and alcohol. ${ }^{23,24}$ In a study conducted in Lahore, paan chewing was identified as major risk factor of oral cancer, followed by niswar, gutka and betel nut chewing. ${ }^{25}$ These findings were in correspondence to our study in which the students identified betel nut, smoking and chewing tobacco as the common risk factors. Significantly, more dental students were able to identify tobacco smoking and betel nut chewing as causative agents for oral cancer, this was also found in other studies performed by Shrestha et al, Carter and Odgen and Diajil AR. ${ }^{16,26,27}$, while tobacco smoking was substantially identified as major risk factor by medical students. Betel quid with smokeless tobacco chewing have a seven-fold higher risk for developing oral cancer when compared to non-chewers and $90 \%$ of the global smokeless tobacco use burden is in South Asian region particularly Pakistan and India. ${ }^{28-30}$ Human Papilloma Virus is another important cancer causing agent ${ }^{31}$ and only $8 \%$ of the students were able to identify it as a causative factor. A comparative survey that was carried out in Lahore amongst undergraduate dental students found that the third year dental students had better knowledge and information regarding the causal agents, clinical presentation of oral cancer when compared with the final year dental students. ${ }^{18}$ However, in our study comparative analysis between students of different years showed that final year dental students had better knowledge regarding risk factors of oral cancerer. e World Health Organization (WHO) has predicted an increase in the amount of patients suffering from oral cancer every year, extending this rise well into the next several decades. General public awareness regarding the causes, risk factors and clinical presentation of oral cancer is found to be very low, especially in the subcontinent. ${ }^{32}$ Hence, general public awareness is an essential component in dropping the morbidity and mortality rate of patients having oral cancer. Although, it was observed that medical students were adequately aware of different factors that can lead to oral cancer however, significantly more dental students agreed to advise patients about the factors causing oral cancer after graduation. This could be due to the fact that dental students have a better opportunity at routinely examining oral mucosa. These findings are in accordance with the results of the previous researches carried out by Carter \& Odgen, Shrestha et al. and Rickard. ${ }^{16,27,33}$

Squamous cell carcinoma may arise de novo in the form of an indurated area of ulceration which has been present for over a month while others are preceded by certain premalignant conditions like erythroplakia, some forms of leukoplakia or a combination of both. ${ }^{34}$ Both medical and dental students were able to identify the changes associated with oral cancer however, dental students had comparatively more information about the premalignant oral conditions. Non-healing ulcer was the commonly identified clinical presentation of the cancer by both dental and medical students. Students of dentistry were more capable of identifying other cancerous appearances while medical students mostly only acknowledged chronic, non-healing ulcer as an early indication of oral cancer which could be due to the fact that ulcer is the common clinical presentation of cancer in other parts of the body as well. It has been documented that histopathologically erythroplakia and erythro-leukoplakia has more than 50\% malignant transformation rate. ${ }^{35}$ Medical students were more aware of red and white lesions being cancerous, contrary to the study carried out by Carter \& Odgen..$^{27}$ Dental students had more awareness of oral submucous fibrosis, a chronic, progressive scarring disease ${ }^{37}$ with a precancerous potential, when compared to medical students.

The dental and medical students both mutually agreed upon referring patients diagnosed with oral mucosal lesion to a dentist. Oral maxillofacial surgery was the commonly identified department for referral of a suspected patient by both medical and dental undergraduates. Hollows et al. in his study, concluded that majority of the medical and dental practitioners refer suspected patients to oral maxillofacial surgery department within a week, as delays in referral to appropriate department can significantly affect the prognosis of the disease. ${ }^{36}$ This further highlights the need of training the medical students from their undergraduate level. More than half of the medical and dental students reported that they did not have sufficient familiarity related to cancer of oral cavity and wanted more information to be disseminated to them. Most of the medical and dental students wanted information to be provided to them by conducting seminars 
and different presenting complains. In this study it was found that considerably more dental students regularly inspect the oral mucosa when compared with the medical students. This could be due to the fact that dental students have to deal with lesions in oral cavity mainly while medical students and general medical practitioners mostly inspect the oral cavity of patients only when they are under consultation for oral problems. ${ }^{17}$ It was observed in our study that more final year dental students examined the patient's oral mucosa on regular basis as in this year the students have the most clinical exposure. On the other hand it was also observed that medical students tend to screen oral mucosa of patients who were at high risk of developing oral cancer. These findings were in correspondence to the study carried out by Yellowitz and Goodman ${ }^{21,22}$, in which they concluded that medical students and practitioners normally examine the oral mucosa of the patients who are at high risk of oral cancer.

Several predisposing factors are involved in aetiology of oral cancer, predominantly it is related to frequent consumption of tobacco products and alcohol. ${ }^{23,24}$ In a study conducted in Lahore, paan chewing was identified as major risk factor of oral cancer, followed by niswar, gutka and betel nut chewing. ${ }^{25}$ These findings were in correspondence to our study in which the students identified betel nut, smoking and chewing tobacco as the common risk factors. Significantly, more dental students were able to identify tobacco smoking and betel nut chewing as causative agents for oral cancer, this was also found in other studies performed by Shrestha et al, Carter and Odgen and Diajil AR. ${ }^{16,26,27}$, while tobacco smoking was substantially identified as major risk factor by medical students. Betel quid with smokeless tobacco chewing have a seven-fold higher risk for developing oral cancer when compared to non-chewers and $90 \%$ of the global smokeless tobacco use burden is in South Asian region particularly Pakistan and India. ${ }^{28-30}$ Human Papilloma Virus is another important cancer causing agent ${ }^{31}$ and only $8 \%$ of the students were able to identify it as a causative factor. A comparative survey that was carried out in Lahore amongst undergraduate dental students found that the third year dental students had better knowledge and information regarding the causal agents, clinical presentation of oral cancer when compared with the final year dental students. ${ }^{18}$ However, in our study comparative analysis between students of different years showed that final year dental students had better knowledge regarding risk factors of oral cancerer. e World Health Organization (WHO) has predicted an increase in the amount of patients suffering from oral cancer every year, extending this rise well into the next several decades. General public awareness regarding the causes, risk factors and clinical presentation of oral cancer is found to be very low, especially in the subcontinent.$^{32}$ Hence, general public awareness is an essential component in dropping the morbidity and mortality rate of patients having oral cancer. Although, it was observed that medical students were adequately aware of different factors that can lead to oral cancer however, significantly more dental students agreed to advise patients about the factors causing oral cancer after graduation. This could be due to the fact that dental students have a better opportunity at routinely examining oral mucosa. These findings are in accordance with the results of the previous researches carried out by Carter \& Odgen, Shrestha et al. and Rickard. ${ }^{16,27,33}$

Squamous cell carcinoma may arise de novo in the form of an indurated area of ulceration which has been present for over a month while others are preceded by certain premalignant conditions like erythroplakia, some forms of leukoplakia or a combination of both. ${ }^{34}$ Both medical and dental students were able to identify the changes associated with oral cancer however, dental students had comparatively more information about the premalignant oral conditions. Non-healing ulcer was the commonly identified clinical presentation of the cancer by both dental and medical students. Students of dentistry were more capable of identifying other cancerous appearances while medical students mostly only acknowledged chronic, non-healing ulcer as an early indication of oral cancer which could be due to the fact that ulcer is the common clinical presentation of cancer in other parts of the body as well. It has been documented that histopathologically erythroplakia and erythro-leukoplakia has more than $50 \%$ malignant transformation rate. ${ }^{35}$ Medical students were more aware of red and white lesions being cancerous, contrary to the study carried out by Carter \& Odgen. ${ }^{27}$ Dental students had more awareness of oral submucous fibrosis, a chronic, progressive scarring disease ${ }^{37}$ with a precancerous potential, when compared to medical students.

The dental and medical students both mutually agreed upon referring patients diagnosed with oral mucosal lesion to a dentist. Oral maxillofacial surgery was the commonly identified department for referral of a suspected patient by both medical and dental undergraduates. Hollows et al. in his study, concluded that majority of the medical and dental practitioners refer suspected patients to oral maxillofacial surgery department within a week, as delays in referral to appropriate department can significantly affect the prognosis of the disease. ${ }^{36}$ This further highlights the need of training the medical students from their undergraduate level. More than half of the medical and dental students reported that they did not have sufficient familiarity related to cancer of oral cavity and wanted more information to be disseminated to them. Most of the medical and dental students wanted 
information to be provided to them by conducting seminars and information booklets. While only few of the participants preferred information to be disseminated in form of lectures. This further indicates a need in change of traditional teaching methods that is limited to the delivering of lectures only. Student participation in the form of interactive lectures, seminars, oral health campaigns and OPD training sessions will encourage the students to search and collect more information related to oral cancer. History charts for oral examination can be included as a part of history taking and examination by medical students as well.

Some limitations of the study included limited data due to a single center-based study. The sample size was also small. A survey with a larger sample size and incorporating more universities across the country will give more insight into the actual requirement of awareness on the subject of oral cancer and improvements that are required in our teaching strategies nationwide.

\section{CONCLUSION}

It can be concluded from this study that students are deficient in knowledge of different aspects of oral cancer such as its aetiology, risk factors and correlated clinical changes. Some changes in teaching strategies particularly for medical students are indicated as they play a key role in prevention, early diagnosis and management of oral cancer. Different awareness seminars and campaigns regarding oral cancer should be held periodically in dental and medical colleges to enhance the knowledge of the students.

\section{RECOMMENDATIONS}

Our study highlights that students prefer interactive methods of teaching over the traditional lectures, hence, our teaching methodologies should be modified accordingly.

\section{CONFLICT OF INTEREST}

None declared.

\section{REFERENCES}

1. LJ Jin IL, JS Greenspan, NB Pitts, C Scully, S Warnakulasuriya. Global burden of oral diseases: emerging concepts,management and interplay with systemic health. Oral Dis. 2016;22:609-19. https://doi.org/10.1111/odi.12428

2. Mamta Agrawal SP, Shikha Jain, Shipra Maitin. Oral Cancer Awareness of the General Public in Gorakhpur City, India. Asian Pacific J Cancer Prev.13(10):5195-9.

https://doi.org/10.7314/APJCP.2012.13.10.5195
3. arwar \& Saqib CM, 4: 1288773 Cancer prevalence, incidence and mortality rates in Pakistan in 2012. Cogent Med. 2017;4(1).

4. v1.0 G. Cancer incidence and mortality worldwide; IARC Cancer Base No. 11 [Internet]: International Agency for Research on Cancer,; 2013. Available from: http://globocan.iarc.fr.

5. (CRCDM) CRaCDM. Report based on cancer cases registered at SKMCH\&RC from Dec. 1994-Dec. 2016 and in 2016. Shaukat Khanum Memorial Cancer Hospital and Research Center (SKMCH\&RC), 2017.

6. R D Jayasinghe LPGS, H Amarasinghe, M A M Sitheeque. Level of awareness of oral cancer and oral potentially malignant disorders among medical and dental undergraduates. Ceylon Medical Journal 2016;61:77-9.

https://doi.org/10.4038/cmj.v61i2.8289

7. Mittal S, Mahuli A, Hiregoudar M, Ramanarayanan S, Mohandas $\mathrm{U}$, Manjunath $\mathrm{P}$, et al. Knowledge of oral cancer and screening practice of B.Sc. nursing students in Davangere City, India. J Educ Ethics in Dent. 2013;3(1):40-3.

https://doi.org/10.4103/0974-7761.126944

8. Dhanuthai K, Rojanawatsirivej S, Thosaporn W, Kintarak S, Subarnbhesaj A, Darling M, et al. Oral cancer: A multicenter study. Medicina Oral, Patologia Oral y Cirugia Bucal. 2018;23(1):e23-e29.

9. Guha N, Boffetta P, Wünsch Filho V, Eluf Neto J, Shangina O, Zaridze D, et al. Oral health and risk of squamous cell carcinoma of the head and neck and esophagus: results of two multicentric casecontrol studies. Am J epidemiol. 2007;166(10):1159-73.

https://doi.org/10.1093/aje/kwm193

10. Petersen PE. Oral cancer prevention and control-the approach of the World Health Organization. Oral oncol. 2009;45(4):454-60. https://doi.org/10.1016/j.oraloncology.2008.05.023

11. Conway DI, Petticrew M, Marlborough H, Berthiller J, Hashibe M, Macpherson L. Socioeconomic inequalities and oral cancer risk: A systematic review and meta-analysis of case-control studies. Int $j$ cancer. 2008;122(12):2811-9.

https://doi.org/10.1002/ijc.23430

12. Dumitrescu AL, Ibric S, Ibric-Cioranu V. Assessing Oral Cancer Knowledge in Romanian Undergraduate Dental Students. J Cancer Educ. 2014;29(3):506-13.

https://doi.org/10.1007/s13187-014-0659-1

13. Elango JK, Sundaram KR, Gangadharan P, Subhas P, Peter S, Pulayath $\mathrm{C}$, et al. Factors affecting oral cancer awareness in a highrisk population in India. Asian Pac J Cancer Prev. 2009;10(4):627-30.

14. Ghani, Nabillah WM, Doss, Geraldine J, Jamaluddin, Marhazlinda, et al. Oral Cancer Awareness and its Determinants among a Selected Malaysian Population. Asian Pacific J Cancer Prev. 2013;14(3):195763.

https://doi.org/10.7314/APJCP.2013.14.3.1957

15. Tomar SL, Logan HL. Florida adults' oral cancer knowledge and examination experiences. J public health dent. 2005;65(4):221-30. 
https://doi.org/10.1111/j.1752-7325.2005.tb03022.x

16. Shrestha A, Marla V, Shrestha S, Agrawal D. Awareness of Undergraduate Dental and Medical Students Towards Oral Cancer. J Cancer Educ. 2017;32(4):778-83.

https://doi.org/10.1007/s13187-016-1023-4

17. Soares TRC, Carvalho MEdA, Pinto LSS, Falcão CA, Matos FTC, Santos TC. Oral cancer knowledge and awareness among dental students. Brazilian Journal of Oral Sciences. 2014;13:28-33. https://doi.org/10.1590/1677-3225v13n1a06

18. Kazmi F, Chaudhary MA, Mumtaz M, Bhatti MUD, Khawaja N. Oral cancer knowledge and awareness amongst undergraduate dental students of Lahore-Pakistan. Pak Oral Dent J. 2011;31(1)62-65.

19. Ramaswamy P, Uday G, Sreenivasulu P, Kumar BP, Khaitan T, Geethika V. Awareness about Oral Cancer among Dental Postgraduate Students in the State of Andhra Pradesh, India. J Cancer Educ. 2014;29(4):665-8.

https://doi.org/10.1007/s13187-014-0620-3

20. Warnakulasuriya K, Harris C, Scarrott D, Watt R, Gelbier S, Peters $\mathrm{T}$, et al. Oral cancer: an alarming lack of public awareness towards oral cancer. Br dent j. 1999;187(6):319-22.

https://doi.org/10.1038/sj.bdj.4800269

21. Yellowitz JA, Goodman HS. Assessing physicians'and Dentists'oral cancer knowledge, opinions and practices. J Am Dent Assoc. 1995;126(1):53-60.

https://doi.org/10.14219/jada.archive.1995.0024

22. Goodman HS, Yellowitz JA, Horowitz AM. Oral Cancer Prevention. The Role of Family Practitioners. Arch Fam Med. 1995;4:628-36.

https://doi.org/10.1001/archfami.4.7.628

23. Blot WJ, McLaughlin JK, Winn DM, Austin DF, Greenberg RS, Preston-Martin S, et al. Smoking and drinking in relation to oral and pharyngeal cancer. Cancer research. 1988;48(11):3282-7.

24. Johnson N. Tobacco use and oral cancer: a global perspective. J dent educ. 2001;65(4):328-39.

25. Riaz F, Asma Nazir H, Tariq H, Sohail H, Gul Khattak S, Ali Khan $\mathrm{H}$, et al. Risk Factors of Oral Cancer in Lahore, Pakistan: A Case Control Design. Proceedings FZPGMI. 2015;29:47-54

26. Diajil AR. Awareness and knowledge of oral cancer among final year undergraduate dental students in Baghdad-Iraq. J Baghdad Coll
Dent. 2013;25(3): 69-79.

https://doi.org/10.12816/0015000

27. Carter LM, Ogden GR. Oral cancer awareness of undergraduate medical and dental students. BMC Medical Education. 2007;7(1):44. https://doi.org/10.1186/1472-6920-7-44

28. Khan Z, Tönnies J, Müller S. Smokeless tobacco and oral cancer in South Asia: a systematic review with meta-analysis. J cancer epidemiol. 2014;2014.

29. Merchant A, Husain SS, Hosain M, Fikree FF, Pitiphat W, Siddiqui $\mathrm{AR}$, et al. Paan without tobacco: an independent risk factor for oral cancer. Int j cancer. 2000;86(1):128-31. https://doi.org/10.1002/(SICI)1097-0215(20000401)86:1<128::AIDIJC20>3.0.CO;2-M

30. Simard EP TL, Jemal A. International trends in head and neck cancer incidence rates: differences by country, sex and anatomic site. Oral Oncol 2014;50:387-403.

https://doi.org/10.1016/j.oraloncology.2014.01.016

31. Kreimer AR, Clifford GM, Boyle P, Franceschi S. Human papillomavirus types in head and neck squamous cell carcinomas worldwide: a systematic review. Cancer Epidemiol Prev Biomarkers. 2005;14(2):467-75

https://doi.org/10.1158/1055-9965.EPI-04-0551

32. T N. Tobacco and alcohol misuse of oral cancer. 6th Hiroshima Conf Educ Sci Dent BioDental Educ Res Tower next 50 years. 2015:132-6.

33. Rikard-Bell G, Groenlund C, Ward J. Australian dental students' views about smoking cessation counseling and their skills as counselors. J Pub Health Dent. 2003;63:200-206. https://doi.org/10.1111/j.1752-7325.2003.tb03500.x

34. Conway DI ML, Gibson J, Binnie VI Oral cancer: prevention and detection in primary dental healthcare. . Prim dent care 2002;9(4):11923.

https://doi.org/10.1308/135576102322481938

35. Bouquot JE, Ephros H. Erythroplakia: the Dangerous Red Mucosa. Pract Perio Aesthet Dent. 1995;7.

36. Hollows P, McAndrew PG, Perini MG. Delays in the Referral and Treatment of Oral Squamous Cell Carcinoma. Br Dent J. 2000;188 https://doi.org/10.1038/sj.bdj.4800449a 